\title{
Drilling analytical model of composite material with pilot hole
}

\author{
Pierre Rahme ${ }^{1, a}$, Yann Landon ${ }^{2}$, Robert Piquet ${ }^{2}$, Frederic Lachaud ${ }^{2}$ \\ and Pierre Lagarrigue ${ }^{2}$ \\ 1 Lebanese University, Mechanical Engineering Department, Faculty of Engineering P.O. Box 27622319, Roumieh, Lebanon \\ 2 Université de Toulouse, INSA, UPS, Mines Albi, ISAE, ICA (Institut Clément Ader), UPS, Bât. 3R1, 118 Route de Narbonne, \\ 31062 Toulouse Cedex 9, France
}

Received 5 September 2014, Accepted 16 November 2015

\begin{abstract}
The use of composite materials machining is increasing more and more in aeronautical. Drilling process is in particular the most used process in the assembly of aeronautical structures. When drilling thick composite laminates, delamination occurs at the exit of the hole. These defects are assumed to be the major defects. They diminish the strength of the structure to failure. To minimize delamination, drilling process with pilot hole is used. In this paper, analytical model for drilling thick composite structures with pilot hole using a twist drill is proposed. This model predicts the critical thrust force at delamination. Different hypotheses of boundary conditions and external loading are proposed. Numerical model is also developed in order to validate the proposed analytical model. Punching tests with twist drill are then realized in order to select the corresponding hypothesis of boundary conditions and external loading. These results may be used to optimize the cutting conditions when drilling thick composite plates with pilot hole.
\end{abstract}

Key words: Drilling / composite materials / pilot hole / twist drill / delamination

\section{Introduction}

Modern aeronautical structures require typically the use of composite materials. The assembly of composite parts requires knowledge in drilling of composite materials. Indeed, drilling of thick composite structures using the conventional twist drill provokes defects at the entry, on the wall and at the exit of the hole [1]. These defects diminish the strength of the structure to failure. Delamination at the exit of the hole is among the serious concerns in drilling composite-based components in practice [2]. It is considered to be the major drilling defect [3-5]. A solution to minimize delamination is to drill a pilot hole [6]. Drilling process with pilot hole minimizes the delamination at exit. This paper focuses on the drilling with pilot hole of thick composite structures using a twist drill in order to minimize the defects at the exit of the hole.

The mechanisms involved in initiation and propagation of delamination at the hole exit were identified by Rahme et al. [5]. Matrix cracks are initiated under the chisel edge of the twist drill and interlaminar delamination is then propagated by the main cutting edges. Tsao et al. [7] developed an analytical approach for the determination of the position of the onset of delamination during

\footnotetext{
${ }^{a}$ Corresponding author: prahme@ul.edu.lb
}

the drilling of composite laminates. Rahme et al. [8] developed an analytical and numerical model to predict the critical thrust force at delamination when drilling thick composite structures.

According to Rahme et al. [9], delamination is directly related to the axial cutting force which in turn depends on the tool geometry and the feed rate per tooth. The optimal drilling thrust force is defined as the minimum force for which delamination is initiated [10]. Delamination at exit can be controlled by taking into account the relationships between machining parameters and forces and torque [11]. The size of the delamination zone has been showed to be related to the thrust force developed during drilling [12]. The critical thrust force at delamination was found by several authors. Lachaud et al. [13] proposed a model which links the axial penetration of the drill bit to the conditions of delamination (crack opening mode I) of the last few plies. Rahme et al. [8] showed the effect of the chisel edge on the critical thrust force at delamination when drilling thick composite material with a twist drill. Rahme et al. [14] showed the effect of various parameters on the critical thrust force at delamination. Hocheng et al. [1] presented the expression of the critical thrust force at delamination when drilling with a twist drill and other special drills as saw drill, core drill and candle stick drill. However, the critical thrust force at delamination 


\section{Nomenclature}

\begin{tabular}{|c|c|}
\hline$a$ & Radius of the drill (mm) \\
\hline$b$ & Radius of the pilot hole ( $\mathrm{mm})$ \\
\hline$q$ & $\begin{array}{l}\text { Uniformly distributed load for hypothesis (a) (and (c) }\left(\mathrm{N} \cdot \mathrm{mm}^{-2}\right) \text {, and circular distributed } \\
\text { load along the circumferential of the pilot hole for hypothesis (b) (N.mm-1) }\end{array}$ \\
\hline$\delta W$ & Elementary virtual work of the external forces $(\mathrm{J})$ \\
\hline$\delta U$ & Virtual variation of the potential energy $(\mathrm{J})$ \\
\hline$\delta U_{d}$ & Variation of the absorbed energy $(\mathrm{J})$ \\
\hline$r$ & Radius of a given point ( $\mathrm{mm})$ \\
\hline$w$ & Transverse displacement of a given point $(\mathrm{mm})$ \\
\hline$Q$ & Shear force intensity $(\mathrm{N})$ \\
\hline$D_{i j}$ & Bending stiffness's (MPa.mm³) \\
\hline$Q_{i j}$ & Stiffness matrix $(\mathrm{MPa})$ \\
\hline$M_{x x}, M_{y y}, M_{x y}$ & Bending moments per unit of width (N.mm.mm-1) \\
\hline$\nu_{r \theta}$ & Poisson's ratio in the polar coordinate \\
\hline$G_{I C}$ & Critical restitution energy in mode I $\left(\mathrm{J} . \mathrm{m}^{-2}\right)$ \\
\hline$F$ & Drilling thrust force $(\mathrm{N})$ \\
\hline$F_{\mathrm{CA}}$ & Critical thrust force at delamination for hypothesis (a) $(\mathrm{N})$ \\
\hline$F_{\mathrm{CB}}$ & Critical thrust force at delamination for hypothesis (b) (N) \\
\hline$F_{\mathrm{CC}}$ & Critical thrust force at delamination for hypothesis (c) (N) \\
\hline$K_{\mathrm{A}}$ & Constant expression corresponding to hypothesis (a) \\
\hline$K_{\mathrm{B}}$ & Constant expression corresponding to hypothesis (b) \\
\hline$K_{\mathrm{C}}$ & Constant expression corresponding to hypothesis (c) \\
\hline CFRP & Carbon fibre reinforced epoxy polymer plates \\
\hline
\end{tabular}

when drilling with pilot hole thick composite structures was not found before.

When drilling composite materials, the contribution of chisel edge to the thrust force is often up to $40-60 \%$ [16]. Delamination can be reduced significantly when drilling with a pilot hole, since the chisel edge no more interacts with material $[15,16]$. Moreover, the chisel edge width has been identified as an important factor contributing to the thrust force and hence delamination [17]. Tsao et al. [18] determined the optimal range of chisel edge length with respect to drill diameter in order to minimize delamination.

In this paper, drilling with pilot hole of thick composite plates using a conventional twist drill is studied. An analytical model for predicting the critical thrust force at delamination is developed when drilling with pilot hole composite laminates using a twist drill. This model is based on fracture mechanics. Different hypotheses for boundary conditions and external loading are proposed. A numerical model is also developed in this paper in order to validate the proposed analytical model. The developed numerical model is based on the finite elements method. Finally, to select the corresponding hypothesis, experimental punching tests are realized on composite laminates. These tests allow finding experimentally the critical thrust force in function of the remaining non-drilled plies under the drill.

A new concept of modelling the exit of the hole, when drilling with pilot hole a composite material, is used in this paper. Indeed, in this model, three new hypotheses of boundary conditions and external loadings are proposed. Moreover, the circular orthotropic plate diameter in this model is taken equal to the diameter of the drill. This diameter varies virtually in this study. This modelling was never developed before. All existing studies used clamped circular plates of diameter equal the length of cracks and applied external circular distributed load only. In all these studies, the length of cracks varies virtually.

\section{Analytical model}

According to Rahme et al. [5], the crack opening mode at the exit of the hole is considered to be due to normal perpendicular to the ply surface. The circular defect is considered to be initiated by the drill in contact with the material during the drilling process [13]. The cracks at the exit of the hole are initiated under the chisel edge and propagated under the action of the two main cutting edges of the twist drill [5]. Drilling with pilot hole process reduces the defects at the exit produced by the chisel edge. The diameter of the pilot hole is taken equal to the diameter of the chisel edge of the drill. A smaller diameter will not completely cover the length of the chisel edge and a greater diameter will also produce delamination that passes the boundary of the hole.

In the present paper, the part of the plate located under the main cutting edges is modelled by a thin circular orthotropic plate with a pilot hole as shown in Figure 1. The thickness of this plate is assumed small with respect to the hole diameter and the shear effect is then neglected. The outer diameter of this plate equals the diameter of the drill (2a). The inner diameter (diameter of the pilot hole) is also similar to the length of the chisel edge $(2 \mathrm{~b})$. 


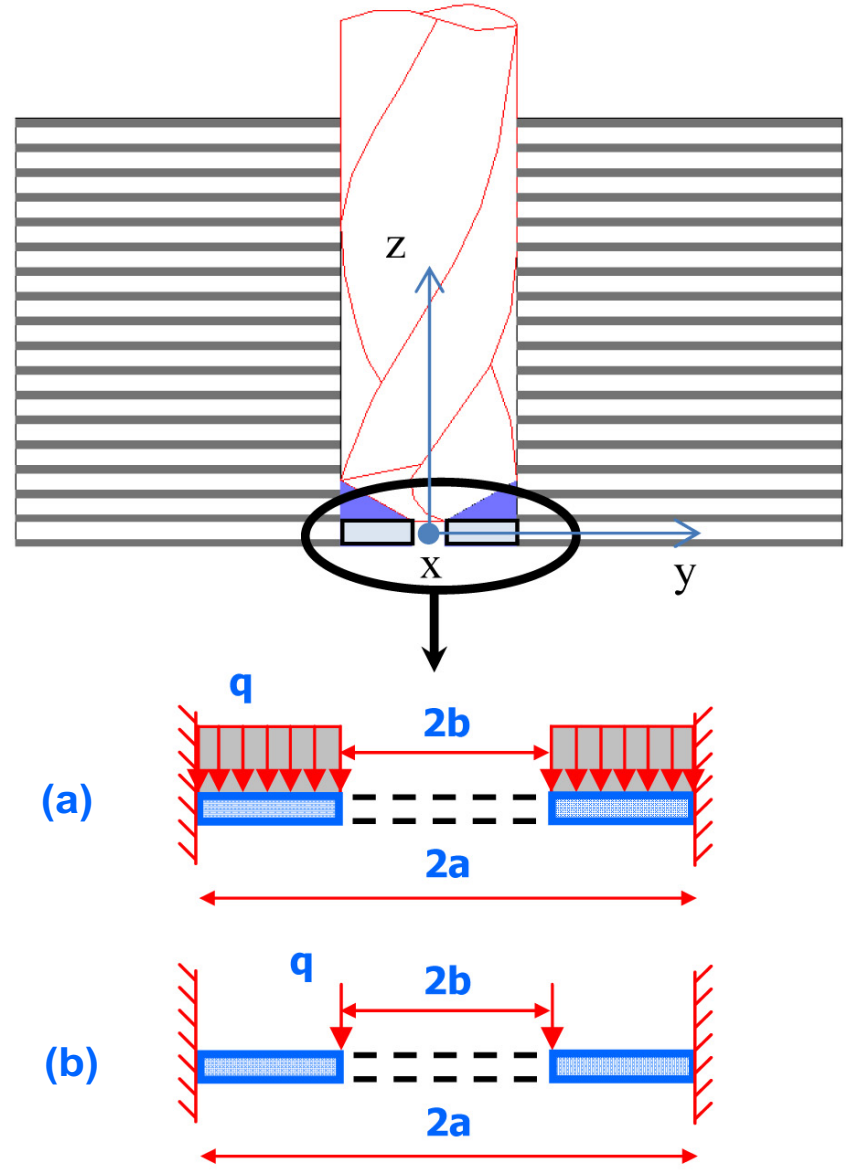

q

(c)

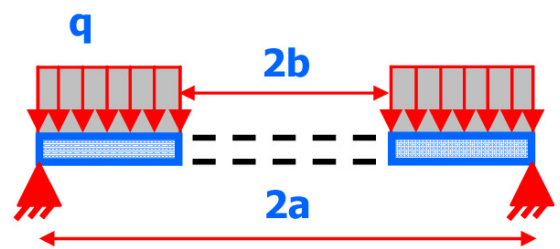

Fig. 1. Different hypotheses for drilling with pilot hole of thick composite plates.

Three hypotheses of boundary conditions and external loading are proposed for this model. A first hypothesis of fixed end plate at the circumferential boundary subjected to a uniformly distributed load is taken (Fig. 1a). This hypothesis takes into account the resistance of the plate to the moment. The fixed end develops a moment reaction. The action of the main cutting edges of the twist drill is modelled by a uniformly distributed load. In the second hypothesis, only action of the edges between the chisel edge and the main cutting edges of the twist drill is taken into account. This action is modelled by a circular distributed load along the circumferential of the pilot hole (Fig. 1b). A third hypothesis, that takes into account the action of the drill main cutting edges but does not develop a moment reaction, is proposed. In this hypothesis, the plate is modelled by a simply supported thin circular plate subjected to a uniformly distributed loading (Fig. 1c). The proposed three hypotheses are original with respect to existing works. Indeed, all exiting hypotheses are based on the clamped circular plates subjected to a central point load. In these hypotheses, a moment reaction is always present. However, in this study, this moment is not observed, according to Rahme et al. [5]. This absence of the moment is modelled in the third hypothesis. Moreover, in all works on drilling of composite materials with pilot hole, a circular distributed load is only considered. In this paper, in the proposed analytical model, a uniformly distributed load is also used.

To calculate the critical thrust force at delamination corresponding to the previous hypotheses, an energetic approach based on the virtual work principle is used. Indeed, at the exit of the plate, the motion of the drill can be associated to a small displacement $\mathrm{d} x$. The thrust force produces an external work on the plate which is a function of the distance $\mathrm{d} x$. This external work tends to produce bending of the plate and to propagate the cracks later. The conservation of energy is written as:

$$
\delta W=\delta U+\delta U_{d}
$$

where $\delta U$ is the virtual variation of the potential energy $U$ and $\delta U_{d}$ is the variation of the energy absorbed by the propagation of cracks.

The radius of the drill (a) is the parameter which varies virtually. Consider $\delta$ a the fictitious length of the cracks. To find the work and the potential energy, the deflection $w(r)$ of the simply supported circular plate of diameter (2a) must be calculated in function of the thrust force. Using the plate theory developed by Timoshenko [19] applied to axisymmetrical circular plates, the equilibrium equation of the plate is given in polar coordinates for small deformations as:

$$
\frac{\mathrm{d}}{\mathrm{d} r}\left[\frac{1}{r} \frac{\mathrm{d}}{\mathrm{d} r}\left(r \frac{\mathrm{d} w(r)}{\mathrm{d} r}\right)\right]=\frac{Q}{D}
$$

$Q$ is the shear per unit of length at any point of the plate as function of the load $q$ for any hypothesis. For an orthotropic material, $D$ is given by:

$$
D=\frac{1}{8}\left(3 D_{11}+3 D_{22}+2 D_{12}+4 D_{66}\right)
$$

with:

$$
\left|D_{i j}\right|=\sum_{k=1}^{n}\left(\overline{Q_{i j}}\right)_{k}\left(\frac{Z_{k}^{3}-Z_{k-1}^{3}}{3}\right)
$$

$Q_{i j}$ are the terms of the rigidity matrix of the plate. $z_{k}$ and $z_{k-1}$ are the position of plies $k$ and $k-1$, respectively, throughout the thickness with respect to the mean plane of the plate.

The elementary virtual work $\delta W$ of the external forces is then:

$$
\delta W=\frac{\partial W}{\partial a} \delta a a
$$

Two cases corresponding to the two external loadings are considered to calculate the total work. For the case of 
Table 1. Critical thrust force at delamination corresponding to three hypotheses.

\begin{tabular}{cc}
\hline Case & Critical thrust force at delamination \\
\hline (a) & $F_{\mathrm{CA}}=8 \pi D \sqrt{\frac{3 G_{\mathrm{IC}}\left(\left(-1-\vartheta_{r \theta}\right) b^{2}+a^{2}\left(\vartheta_{r \theta}-1\right)\right)^{3}\left(a^{2}-b^{2}\right)^{3}}{(a-b) K_{A}}}$ \\
(b) & $F_{\mathrm{CB}}=8 \pi D \sqrt{\frac{G_{\mathrm{IC} b} b\left(\left(-1-\vartheta_{r \theta}\right) b^{2}+a^{2}\left(\vartheta_{r \theta}-1\right)\right)^{3}}{3 K_{B}}}$ \\
(c) & $F_{\mathrm{CC}}=16 \pi D\left(a^{2}-b^{2}\right)^{2}\left(\vartheta_{r \theta}-1\right)^{2} \sqrt{\frac{128 G_{I C}}{b^{4}\left(\vartheta_{r \theta}+1\right) K_{C}}}$ \\
\hline
\end{tabular}

uniformly distributed load (hypothesese (a) and (c)), the work is given by:

$$
W_{a-c}=\int_{0}^{2 \pi} \int_{b}^{a} q w(r) r \mathrm{~d} r \mathrm{~d} \theta
$$

For the case of circular distributed load (hypothesis (b)), the work is:

$$
W_{b}=\int_{0}^{2 \pi} q w(b) r \mathrm{~d} \theta
$$

The virtual variation $\delta U$ of the potential energy $U$ is given by:

$$
2 U=\int_{S}\left[M_{x x} \frac{\partial^{2} w}{\partial x^{2}}+M_{y y} \frac{\partial^{2} w}{\partial y^{2}}+2 M_{x y} \frac{\partial^{2} w}{\partial x \partial y}\right] \mathrm{d} S
$$

Furthermore, the variation of the energy absorbed by the propagation of cracks is given by $\delta U_{d}$. This energy $U_{d}$ is the product of the critical restitution energy corresponding to mode I $\left(G_{\mathrm{IC}}\right)$ and the circular surface:

$$
U_{d}=G_{\mathrm{IC}} S=G_{\mathrm{IC}} \pi a^{2}
$$

The equation of energy conservation is then solved for the critical thrust force at delamination for the three proposed hypotheses. The results corresponding to these hypotheses are shown in Table 1.

The expressions of $K_{\mathrm{A}}, K_{\mathrm{B}}$ and $K_{\mathrm{C}}$ are given in Appendix A.

\section{Numerical validation}

In this section, a numerical model based on the finite elements method is developed in order to validate the analytical model. This axisymmetrical model was developed under the finite elements software Samcef. The same as for the analytical model, fictitious cracks are originally created by adding fictitious material on the circumferential boundary of the plate (Fig. 2). These cracks are used to calculate the restitution energy along the crack corresponding to a given external load.

Moreover, the model predicts the decomposition of the restitution energy with respect to different opening cracks modes. The same material and the same stacking sequences used in experimentation are considered in this section. In this model, modes II and III corresponding to opening cracks are neglected. The restitution energy is calculated using the virtual crack extension method (VCE) integrated in Samcef software. This restitution energy for mode I is determined for each node in front of the circumferential crack. The maximum value of the calculated restitution energy is selected. In the analytical model, constant restitution energy was taken. In reality for an orthotropic material, the resistance of one ply under the drill against delamination is not constant. The fibres resist in tension in the longitudinal direction more than in transverse direction.

The calculation of the maximum restitution energy is found for a number of plies non-drilled remaining under the drill varying from 1 to 6 and in function of the applied external load. A program under Linux and using the script TCL Shell is developed in order to run the calculation under Samcef several time. When the calculated maximum restitution energy equals the critical one, then the corresponding applied external load corresponds to the critical thrust force at delamination.

The boundary conditions of the model are presented in Figure 2a. Figure 2b shows half of the modelled hole. To model the simply supported plate, the thickness of the fictitious material is taken enough thick so that the fixed nodes are sufficiently far from the fictitious cracks. When the distance between the fictitious cracks and the fixed nodes becomes smaller and smaller, the model will be corresponding to the clamped circular plate. In this paper, only the case of uniformly distributed load is validated and compared to the analytical and experimental results in the next sections.

The engineering constants of the composite material used in the analytical and numerical models are found experimentally. A series of characterization tests is realized in order to determine these constants. Table 2 shows the results of the mechanical properties used in the numerical model.

Using the loop cited above, the critical thrust force of crack initiation is calculated for a value of the critical energy release rate of $800 \mathrm{~J} . \mathrm{m}^{-2}$ corresponding to cracks propagation by varying the number of non-delaminated plies and using the VCE method under Samcef. The results of this numerical model will be presented in the results section.

\section{Experimental part}

In this part, the critical thrust force at delamination is found experimentally. Punching tests are realized using tension/compression machine (Instron 8862). Carbon fibre reinforced epoxy polymer plates (CFRP) T800/M21 of thickness $20 \mathrm{~mm}$ are used. Quasi-isotropic plates of sequence $\left[90^{\circ},+45^{\circ}, 0^{\circ},-45^{\circ}\right]_{S 10}$ are made in the laboratory. The thickness of one ply is $0.25 \mathrm{~mm}$. For the used material, the critical restitution energy $G_{\text {IC }}$ corresponding to propagation of cracks is taken equal to $800 \mathrm{~J} \mathrm{Jm}^{-2}$. This value is found experimentally using standard ISO 15024. To punch the remaining non-drilled plies under the drill, standard sharpened twist drill (DIN 1897) 


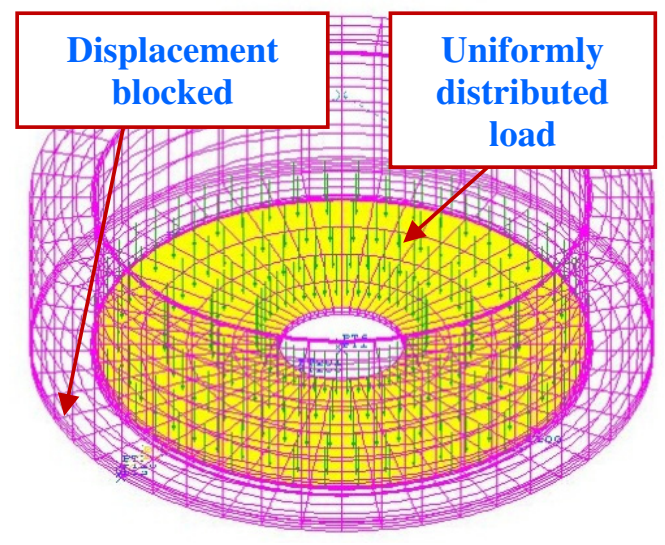

(a)

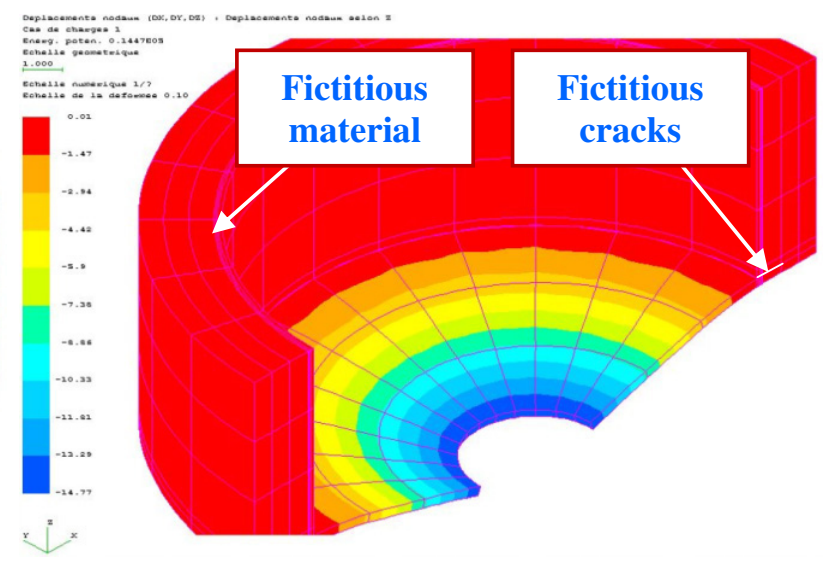

(b)

Fig. 2. Numerical model for drilling thick composite plate with pilot hole. (a) Boundary conditions and (b) deflection of one ply remaining under the drill.

Table 2. Engineering constants of the composite material used.

\begin{tabular}{cccccc}
\hline T21/M800 & $E_{l}(\mathrm{GPa})$ & $E_{t}(\mathrm{GPa})$ & $\nu_{l t}$ & $G_{l t}(\mathrm{GPa})$ & $G_{\mathrm{IC}}\left(\mathrm{J} \mathrm{m}^{-2}\right)$ \\
\hline Value & 160 & 7.84 & 0.4 & 5.22 & 800 \\
\hline
\end{tabular}

tapered without thinning of the chisel edge of diameter $15.8 \mathrm{~mm}$ is used. This twist drill was also used to drill a blind hole with pilot hole. The number of plies remaining non-drilled varies from 1 to 6 plies. The diameter of the pilot hole is taken equal to the length of the chisel edge $3.9 \mathrm{~mm}$. Figure 3 shows a punching test on the composite plate using a twist drill and the corresponding setup. The same setup was also used to drill the pilot hole and the blind hole. The used setup is fixed on the tension/compression machine. The composite plate is fixed in the setup using three bolts shown on the figure. The part of the setup located under the plate at the exit of the hole is drilled so the remaining non-drilled plies can be pushed without backup support. An example of the applied force curve by the machine during the punching test is shown as function of the displacement in Figure 4. The maximum force on the curve corresponds to the critical thrust force at delamination. The punching test is repeated by varying the number of non-drilled plies remaining under the drill. The critical thrust force is then plotted in function of the number of delaminated non-drilled plies.

Figure 4 shows the curve of the thrust force during the punching test of one non-drilled ply remaining under the drill. The thrust force increases in function of the drill displacement and reaches in this case a maximum value of $260 \mathrm{~N}$. This value corresponds to critical thrust force at delamination for one non-drilled ply.

\section{Results and discussion}

The critical thrust forces at delamination found in the previous sections are presented in this paragraph. The results of the three hypotheses are compared with the numerical model and the experimental results of punching

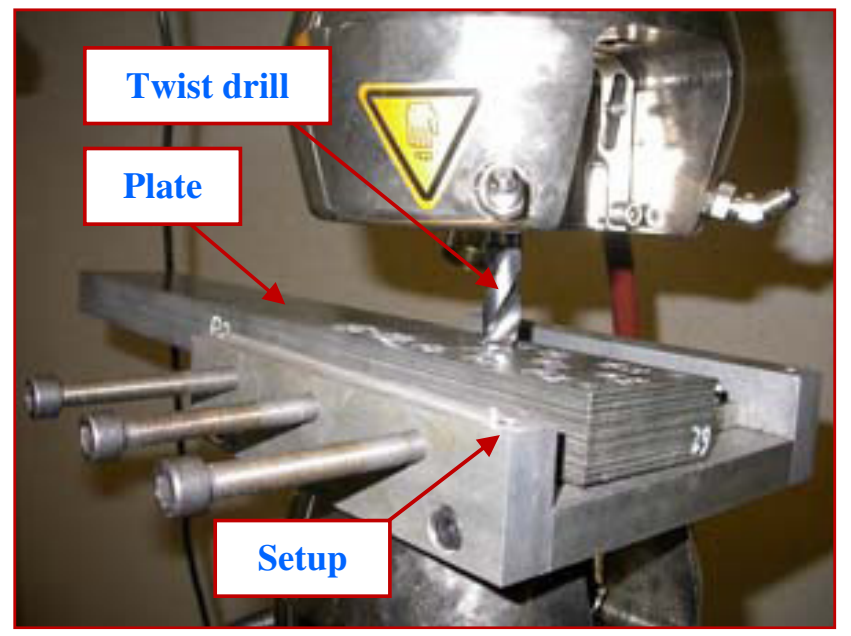

Fig. 3. Experimental punching tests using Instron tension/compression machine.

test. The critical thrust force is plotted in function of the number of delaminated plies remaining under the drill. Figure 5 presents the comparison for critical thrust forces at delamination of composite structures when drilling with pilot hole of the three analytical hypotheses with experimentation as well as with the numerical model.

In Figure 5, the numerical model validates the analytical model. An error of $4 \%$ between the models is found for one delaminated ply and a maximum error of $24 \%$ is obtained for five delaminated ply. This last error for five delaminated ply may be due to the fact that the analytical model does not take into account the shear.

At the same time, a large critical thrust force corresponding to hypothesis (a) (fixed end plate with uniformly distributed load) is presented by the analytical 


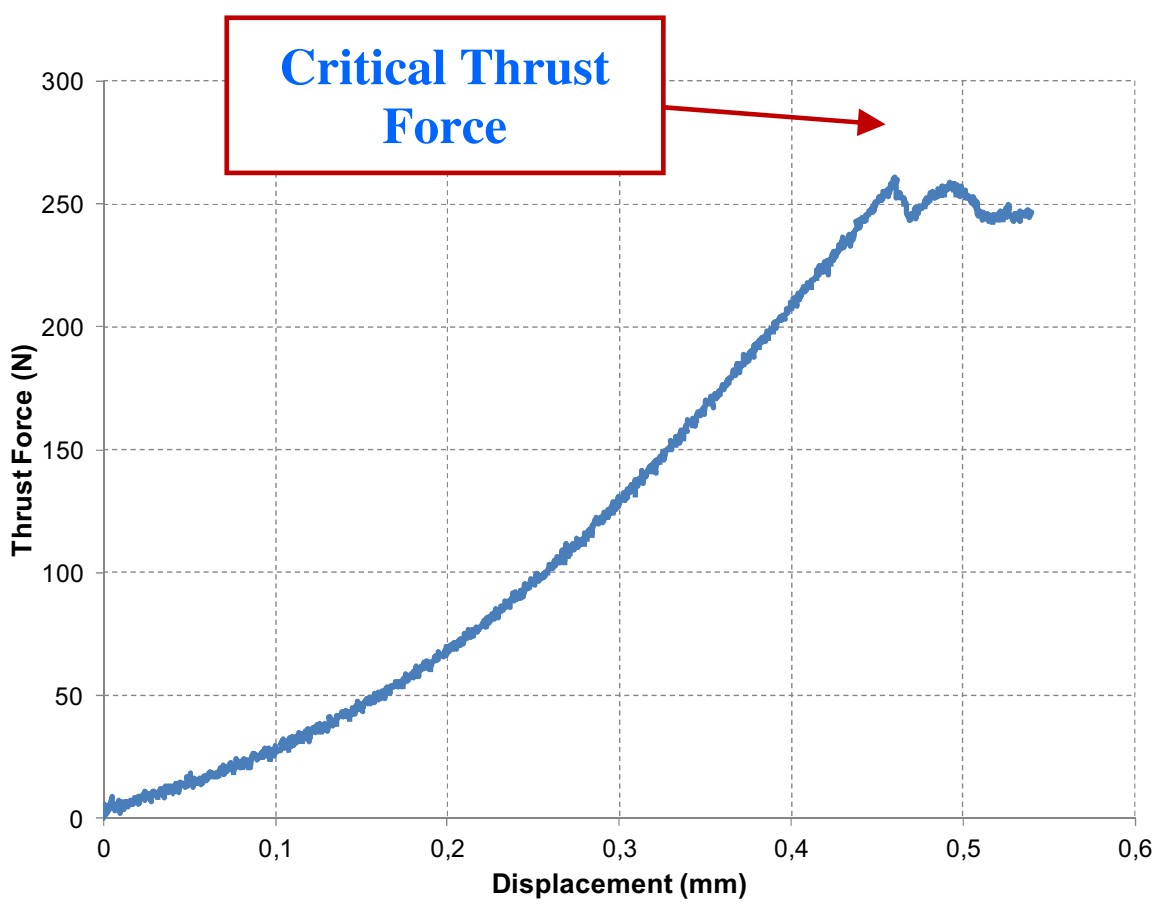

Fig. 4. Punching test, curve of the thrust force for one ply remaining under the drill in function of the displacement.

model. The results of this hypothesis are relatively outsized with respect to experimental and numerical results. The critical thrust force of hypothesis (b) with circular distributed load is also bigger than experimental results. The third hypothesis (c) for the simply supported plate subjected to a uniformly distributed load is the nearest to experimentation. This shows that the fixed end hypothesis does not meet with the experimental results. This hypothesis can be used to model drilling with exit backup support. The simply supported plate is in this case the suitable hypothesis to model drilling without exit back-up support. The results of the third hypothesis of analytical model validate the choice of the boundary conditions and the external loading. Indeed, the results of experimentation and modelling are close. For six plies under the drill, the results are very close with an error of $8 \%$. On the other hand, for two delaminated plies, a maximum error of $28 \%$ is found. However, the proposed analytical model is always conservative since it presents critical thrust force at delamination less than the results found in experimentation. These results correlate with the results found by Rahme et al. [5]. The hypothesis of the inexistence of the moment reaction at the exit of the hole is proved. When the critical thrust force corresponding for a couple tool/material is found for drilling with pilot hole, it can be used to determine the critical cutting conditions at delamination.

\section{Conclusion}

Drilling process with pilot hole is used to minimize delamination at exit of the hole for thick composite struc- ture. The pre-drilled pilot hole eliminates the effect of chisel edge which is important on delamination. In this paper, an analytical model is developed for drilling with pilot hole thick composite plates using a twist drill. This analytical model predicts the critical thrust force at delamination corresponding to propagation of the cracks for the last plies at the exit. Three hypotheses of boundary conditions and external loading are proposed for drilling with pilot hole process using a twist drill. A numerical model is developed in order to validate the proposed analytical model. Moreover, punching experimental tests have been realized in order to choose the corresponding boundary conditions and external loading. The simply supported plate subjected to a uniformly distributed load corresponds to the closest results between analytical model and experimentation. These results can be used to optimize the cutting conditions when drilling with pilot hole composite structures.

Acknowledgements. We are grateful for the materials resources provided by AIRBUS Toulouse France. We thank Cédric Leroy, Benoît Marguet and Jacques Bourriquet for helping and supporting us in this work. This work was carried out within the context of the working group Manufacturing 21 which gathers 16 French research laboratories. The topics approached are:

\footnotetext{
- The modeling of the manufacturing process,

- The virtual machining,

- The ermerging of new manufacturing methods.
} 


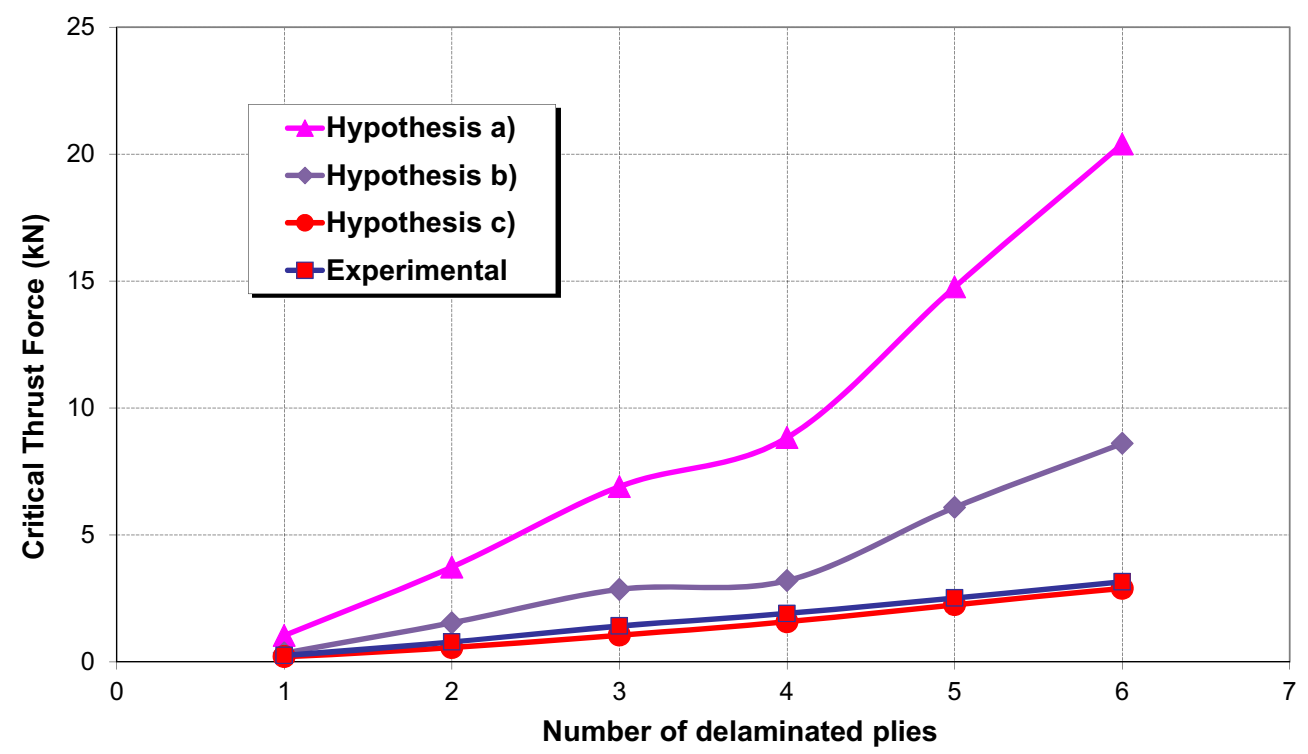

Fig. 5. Comparison between different hypotheses of analytical model and experimentation results.

\section{Appendix A}

For a given composite material, coefficient $D^{\prime}$ is taken as:

$$
D^{\prime}=\frac{\left(D_{11}+D_{22}\right)}{2}+\frac{\left(D_{12}+2 D_{66}\right)}{3}
$$

The coefficients $K_{\mathrm{A}}, K_{\mathrm{B}}$ and $K_{\mathrm{C}}$ used in the critical thrust force formulas are:

See equations (A.2)-(A.4) next pages.

\section{References}

[1] H. Hocheng, C.C. Tsao, The path towards delaminationfree drilling of composite materials, J. Mater. Process. Technol. 167 (2005) 251-264

[2] C.C. Tsao, H. Hocheng, Y.C. Chen, Delamination reduction in drilling composite materials by active backup force, CIRP Annals - Manufacturing Technology 61 (2012) 91-94

[3] P. Rahme, Y. Landon, P. Lagarrigue, R. Piquet, F Lachaud, Drilling of thick composite structures with pilot hole using a twist drill, Proceedings of 16th European Conference on Composite Materials (ECCM16), Seville, Spain, 2014

[4] R. Piquet, B. Ferret, F. Lachaud, P. Swider, Experimental analysis of drilling damage in thin carbon/epoxy plate using special drills, Compos. Part A 31 (2000) 1107-1115

[5] P. Rahme, Y. Landon, P. Lagarrigue, R. Piquet, F. Lachaud, Study into causes of damage to carbon epoxy composite material during the drilling process, Int. J. Mach. Machinab. Mater. 3 (2008) 309-325

[6] M.S. Won, C.K.H. Dharan, Chisel edge and pilot hole effects in drilling composite laminates, J. Manufact. Sci. Eng. 124 (2002) 242-247

[7] C.C. Tsao, W.C. Chen, Prediction of the location of delamination in the drilling of composite laminates, Int. J. Mater. Process. Technol. 70 (1997) 185-189
[8] P. Rahme, Y. Landon, P. Lagarrigue, R. Piquet, F Lachaud, B. Marguet, J. Bourriquet, C. Le Roy, Chisel edge effect on delamination when drilling thick composite materials with a twist drill, SAE Int. J. Aerospace 1 (2009) 776-781

[9] P. Rahme, Y. Landon, P. Lagarrigue, F. Lachaud, R. Piquet, Drilling thick composite materials using large diameter drills, Int. J. Machin. Machinab. Mater. 10 (2011) 202-221

[10] H. Hocheng, C.K.H. Dharan, Delamination during drilling in composite laminates, ASME J. Eng. Ind. 112 (1990) 236-239

[11] F. Veniali, A. Di Ilio, V. Tagliaferri, An experimental study of the drilling of aramid composites, J. Energy Resour. Technol 117 (1995) 271-278

[12] W. Koenig, C. Wulf, P. Grass, H. Willerscheid, Machining of fiber reinforced plastics, Ann. CIRP 34 (1984) 537-548

[13] F. Lachaud, R. Piquet, F. Collombet, L. Surcin, Drilling of composite structures, Compos. Struct. 52 (2001) 511516

[14] P. Rahme, Y. Landon, P. Lagarrigue, R. Piquet, F Lachaud, B. Marguet, J. Bourriquet, C. Le Roy, Drilling of think composite structures - State of the art, SAE International Conference, Toulouse, France, 2006

[15] P. Rahme, Y. Landon, R. Piquet, F Lachaud, P. Lagarrigue, Analytical model for pre-drilled thick composite plates, Joint Conference on Mechanical, Design Eng. Adv. Manuf. - JCM14, Toulouse, France, 2014

[16] S. Jain, D.C.H. Yang, Delamination-Free drilling of composite laminates, ASME Mater. Div. Publ., MD, Anaheim, CA, USA, 1992, pp. 45-59

[17] S. Jain, D.C.H. Yang, Effects of feed rate and chisel edge on delamination in composites drilling, J. Eng. Ind. 115 (1993) 398-405

[18] C.C. Tsao, H. Hocheng, The effect of chisel length and associated pilot hole on delamination when drilling composite materials, Int. J. Mach. Tools Manuf. 43 (2003) 1087-1092

[19] S. Timoshenko, S. Woinowsky-Krieger, Theory of plates and shells, Mcgraw-Hill, 1959, ISBN 13: 9780070647794 


$$
\begin{aligned}
& K_{\mathrm{A}}=96 b^{6}\left[\frac{1}{2}\left(D-\frac{3 D^{\prime}}{8}\right)\left(1+\vartheta_{r \theta}\right)^{3} b^{6}+\left(\left(D-\frac{9 D^{\prime}}{8}\right) \vartheta_{r \theta}+\frac{2 D_{12}}{3}+D-\frac{2 D_{66}}{3}-\frac{D^{\prime}}{8}\right) a^{2}\left(1+\vartheta_{r \theta}\right) b^{4}\right. \\
& \left.-\frac{3}{2}\left(\vartheta_{r \theta}-1\right)\left(D-\frac{3 D^{\prime}}{D}\right)\left(1+\vartheta_{r \theta}\right)^{2} a^{4} b^{2}+\left(\vartheta_{r \theta}+1\right)\left(\left(D-\frac{3 D^{\prime}}{D}\right) \vartheta_{r \theta}^{2}+\frac{3 \vartheta_{r \theta} D^{\prime}}{4}+\frac{D^{\prime}}{8}-\frac{2 D_{12}}{3}-D+\frac{2 D_{66}}{3}\right) a^{6}\right] \\
& \times \ln \left(\frac{b}{a}\right)^{2}+24 b^{4}\left[-3\left(\left(D-\frac{3 D^{\prime}}{8}\right) \vartheta_{r \theta}^{2}+\left(\frac{4 D}{3}-\frac{3 D^{\prime}}{4}\right) \vartheta_{r \theta}-\frac{2 D_{66}}{9}-\frac{D^{\prime}}{24}+\frac{2 D_{12}}{9}+\frac{D}{3}\right)\left(1+\vartheta_{r \theta}\right) b^{8}\right. \\
& +8 a^{2} b^{6}\left(\left(D-\frac{3 D^{\prime}}{8}\right) \vartheta_{r \theta}^{3}+\left(-\frac{9 D^{\prime}}{32}+\frac{7 D}{4}\right) \vartheta_{r \theta}^{2}+\left(\frac{D_{66}}{3}+D-\frac{D_{12}}{3}-\frac{5 D^{\prime}}{16}\right) \vartheta_{r \theta}+\frac{D}{4}-\frac{D_{12}}{6}+\frac{D_{66}}{6}-\frac{5 D^{\prime}}{32}\right) \\
& -6 a^{4} b^{4}\left(\left(D-\frac{3 D^{\prime}}{8}\right) \vartheta_{r \theta}^{3}+\left(\frac{3 D^{\prime}}{4}+\frac{4 D}{3}\right) \vartheta_{r \theta}^{2}+\left(\frac{10 D_{66}}{9}-D-\frac{10 D_{12}}{9}-\frac{D^{\prime}}{24}\right) \vartheta_{r \theta}-\frac{4 D}{3}+\frac{D^{\prime}}{2}\right) \\
& +2 a^{6} b^{2}\left(\left(D+\frac{9 D^{\prime}}{8}\right) \vartheta_{r \theta}^{2}+\left(\frac{4 D_{66}}{3}-\frac{4 D_{12}}{3}+\frac{D^{\prime}}{4}-4 D\right) \vartheta_{r \theta}-\frac{2 D_{66}}{3}-\frac{7 D^{\prime}}{8}+\frac{2 D_{12}}{3}+3 D\right) a^{8}\left(\vartheta_{r \theta}-1\right) \\
& \left.\times\left(\left(D-\frac{3 D^{\prime}}{8}\right) \vartheta_{r \theta}^{2}+\frac{3 D^{\prime} \vartheta_{r \theta}}{4}+\frac{D^{\prime}}{8}-D+\frac{2 D_{66}}{3}-\frac{2 D_{12}}{3}\right)\right] \ln \frac{b}{a}+(a+b)\left[b ^ { 1 0 } \left(\left(-13 D+\frac{39 D^{\prime}}{8}\right) \vartheta_{r \theta}^{3}\right.\right. \\
& \left.+\left(\frac{117 D^{\prime}}{8}+9 D\right) \vartheta_{r \theta}^{2}+\left(45 D-\frac{111 D^{\prime}}{8}+16 D_{66}-16 D_{12}\right) \vartheta_{r \theta}+23 D-\frac{93 D^{\prime}}{8}-8 D_{12}+8 D_{66}\right)+41 a^{2} b^{8} \\
& \times\left(\left(D-\frac{3 D^{\prime}}{8}\right) \vartheta_{r \theta}^{3}+\left(-\frac{135 D^{\prime}}{328}-\frac{3 D}{41}\right) \vartheta_{r \theta}^{2}+\left(\frac{51 D}{41}-\frac{33 D^{\prime}}{328}-\frac{16 D_{66}}{41}+\frac{16 D_{12}}{41}\right) \vartheta_{r \theta}+\frac{71 D}{41}-\frac{237 D^{\prime}}{328}-\frac{8 D_{12}}{41}+\frac{8 D_{66}}{41}\right) \\
& -46 a^{4} b^{6}\left(\left(D-\frac{3 D^{\prime}}{8}\right) \vartheta_{r \theta}^{3}+\left(\frac{45 D^{\prime}}{184}+\frac{9 D}{23}\right) \vartheta_{r \theta}^{2}+\left(\frac{21 D}{23}-\frac{51 D^{\prime}}{184}+\frac{8 D_{66}}{23}-\frac{8 D_{12}}{23}\right) \vartheta_{r \theta}-\frac{37 D}{23}+\frac{99 D^{\prime}}{184}-\frac{4 D_{12}}{23}+\frac{4 D_{66}}{23}\right) \\
& +22 a^{6} b^{4}\left(\left(D-\frac{3 D^{\prime}}{8}\right) \vartheta_{r \theta}^{3}+\left(\frac{63 D^{\prime}}{88}+\frac{3 D}{11}\right) \vartheta_{r \theta}^{2}+\left(-\frac{27 D}{11}+\frac{21 D^{\prime}}{88}+\frac{8 D_{66}}{11}-\frac{8 D_{12}}{11}\right) \vartheta_{r \theta}+\frac{13 D}{11}-\frac{27 D^{\prime}}{88}+\frac{4 D_{12}}{11}-\frac{4 D_{66}}{11}\right) \\
& \left.-5 a^{8} b^{2}\left(D-\frac{3 D^{\prime}}{8}\right)\left(\vartheta_{r \theta}+\frac{1}{5}\right)\left(\vartheta_{r \theta}-1\right)^{2}+a^{10}\left(\vartheta_{r \theta}-1\right)^{3}\left(D-\frac{3 D^{\prime}}{8}\right)\right]
\end{aligned}
$$

$$
\begin{aligned}
K_{\mathrm{B}}= & \left(b^{2}\left(1+\vartheta_{r \theta}\right) \ln \frac{b}{a}+\frac{1}{2}\left(a^{2}-b^{2}\right)\left(\vartheta_{r \theta}-1\right)\right)\left[-2 D^{\prime}\left(1+\vartheta_{r \theta}\right)^{2} b^{3}+\frac{16 D}{3}\left(1+\vartheta_{r \theta}\right)^{2} b^{2}-\frac{16 a^{2} b^{2} D}{3}\left(\vartheta_{r \theta}^{2}-1\right) \ln \frac{b}{a}\right. \\
& +a^{2} b\left(2 D^{\prime} \vartheta_{r \theta}^{2}-8 D^{\prime} \vartheta_{r \theta}+\frac{D_{11}}{3}+\frac{D_{22}}{3}+\frac{22 D_{12}}{3}-\frac{20 D_{66}}{3}+\frac{a^{2}-b^{2}}{2}\left(\left(-2 D^{\prime} \vartheta_{r \theta}^{2}-8 D^{\prime} \vartheta_{r \theta}+\frac{7 D_{11}}{3}+\frac{7 D_{22}}{3}+\frac{26 D_{12}}{3}-4 D_{66}\right)\right.\right. \\
& \left.\left.\times b^{3}+\frac{16 D b^{2}}{3}\left(\vartheta_{r \theta}^{2}-1\right)+2 D^{\prime} a^{2} b\left(\vartheta_{r \theta}-1\right)^{2}-16 D \frac{a^{2}}{3}\left(\vartheta_{r \theta}-1\right)^{2}\right)\right]
\end{aligned}
$$


P. Rahme et al.: Mechanics \& Industry 17, 513 (2016)

$$
\begin{aligned}
K_{\mathrm{C}}= & {\left[\left(-9 D^{\prime}+24 D\right) \vartheta_{r \theta}^{3}+\left(9 D^{\prime}+24 D\right) \vartheta_{r \theta}^{2}+\left(48 D_{66}-24 D+21 D^{\prime}-16 D_{12}\right) \vartheta_{r \theta}-16 D_{12}+3 D^{\prime}+16 D_{66}\right) \frac{b^{4}}{48} } \\
& \left.+\frac{\left(\left(24 D-9 D^{\prime}\right) \vartheta_{r \theta}^{2}+18 D^{\prime} \vartheta_{r \theta}-16 D_{12}+16 D_{66}-24 D+3 D^{\prime}\right)\left(\vartheta_{r \theta}+1\right) a^{2} b^{2}}{24}+\frac{D a^{4}}{2}\left(\vartheta_{r \theta}-1\right)\right] \ln \left(\frac{b}{a}\right)^{2} \\
& +\frac{b^{4}\left(a^{2}-b^{2}\right)\left(\vartheta_{r \theta}+1\right)}{4}\left[-4 D\left(a^{2}+b^{2}\right)\left(\vartheta_{r \theta}-1\right) \ln b+\left(\left(3 D-\frac{9 D^{\prime}}{8}\right) \vartheta_{r \theta}^{3}+\left(5 D-\frac{9 D^{\prime}}{8}\right) \vartheta_{r \theta}^{2}\right.\right. \\
& \left.+\left(-5 D+\frac{25 D^{\prime}}{8}-\frac{8 D_{12}}{3}+\frac{8 D_{66}}{3}\right) \vartheta_{r \theta}+\frac{8 D_{66}}{3}-\frac{8 D_{12}}{3}+\frac{7 D^{\prime}}{8}-3 D\right) b^{2}+\left(\left(D-\frac{3 D^{\prime}}{8}\right) \vartheta_{r \theta}^{3}+\left(3 D+\frac{3 D^{\prime}}{8}\right) \vartheta_{r \theta}^{2}\right. \\
& \left.\left.+\left(D+\frac{11 D^{\prime}}{8}+\frac{4 D_{66}}{3}-\frac{4 D_{12}}{3}\right) \vartheta_{r \theta}-5 D+\frac{5 D^{\prime}}{8}+\frac{4 D_{66}}{3}-\frac{4 D_{12}}{3}\right) a^{2}\right] \ln \frac{b}{a}+\frac{\left(a^{2}-b^{2}\right)}{96}\left[48 D b^{4}\left(a^{2}+b^{2}\right)\left(\vartheta_{r \theta}^{2}-1\right)\right. \\
& \times \ln \left(\frac{b}{a}\right)^{2}-48 D b^{4}\left(a^{2}-b^{2}\right)\left(\vartheta_{r \theta}^{2}-1\right) \ln b+\left(\left(\left(13 D-\frac{39 D^{\prime}}{8}\right) \vartheta_{r \theta}^{4}+78 D \vartheta_{r \theta}^{3}+\left(88 D+\frac{99 D^{\prime}}{4}-26 D_{12}+26 D_{66}\right) \vartheta_{r \theta}^{2}\right.\right. \\
& \left.+\left(-78 D+42 D^{\prime}-44 D_{12}+44 D_{66}\right) \vartheta_{r \theta}-101 D+\frac{81 D^{\prime}}{8}-26 D_{12}+26 D_{66}\right) b^{4}-2\left(\left(D-\frac{3 D^{\prime}}{8}\right) \vartheta_{r \theta}^{2}\right. \\
& \left.\left.\left.+\left(8 D-\frac{3 D^{\prime}}{4}\right) \vartheta_{r \theta}+7 D-\frac{27 D^{\prime}}{8}-2 D_{12}+2 D_{66}\right)\left(\vartheta_{r \theta}-1\right)^{2} a^{2}\left(a^{2}+2 b^{2}\right)\right)\left(a^{2}-b^{2}\right)\right]
\end{aligned}
$$

